\title{
Skeletal muscle expression of class II histocompatibility antigens (HLA-DR) in polymyositis and other muscle disorders with an inflammatory infiltrate
}

\author{
J A ZUK, A FLETCHER
}

From the Department of Histopathology, level III, phase III, Leicester Royal Infirmary, Leicester

SUMMARY Muscle biopsy specimens with a pronounced inflammatory component were evaluated for myocyte expression of class II histocompatibility antigens (HLA-DR) by immunohistochemical techniques. All 15 cases of polymyositis were positive; six cases of muscular dystrophy (two Duchenne, four facio-scapulo-humeral), and one case of acute denervation (motor neurone disease) were negative, despite having a comparably intense mononuclear infiltrate. Twelve entirely normal biopsy specimens were also negative for HLA-DR expression.

Expression of this membrane glycoprotein may have a clinically important aetiological role in polymyositis, and demonstration of its presence may prove useful as a marker for this disorder in selected problematic biopsy specimens.

Although the primary aetiological factors responsible for causing polymyositis remain to be fully identified, immunological mechanisms of both cell mediated and humoral type are clearly important. ${ }^{12}$ The deposition of immunoglobulins and complement within inflamed muscle has been extensively studied ${ }^{34}$ as has the infiltrating mononuclear cell population, using monoclonal antibodies to lymphocytes and their subsets on tissue sections. ${ }^{5-9}$ In vitro there is increased lymphocyte mediated autoreactivity to skeletal muscle in polymyositis, ${ }^{1011}$ and this type of cell mediated immune reaction is considered to be of major aetiological importance.

Target cell expression of HLA antigens is vital in the generation of cell mediated immune reactions. These membrane glycoproteins, of which there are two main families - class I (HLA-A,B,C) and class II (HLADR)-have a central immunoregulatory role. $T$ lymphocytes must recognise these components to become activated by antigen. ${ }^{12}{ }^{13}$ Specifically, the T8 (suppressor/cytotoxic) subset of lymphocytes interact with class I antigens and T4 (inducer/helper) subset with class II. ${ }^{12} 14$ Class I antigens are widely distributed in normal tissues in man, being present on the cell membranes of virtually all nucleated cells. ${ }^{15}$ Class II

Accepted for publication 19 November 1987 expression is, however, more restricted, being found predominantly on cells of the lymphoreticular system, vascular endothelium, and some epithelia. ${ }^{16}$ Normal skeletal muscle does not express HLA-DR. ${ }^{17}$

Aberrant expression of class II histocompatibility antigens is considered to have a clinically important role in the aetiology and pathogenesis of various autoimmune disorders, including autoimmune thyroiditis, ${ }^{18}$ type I diabetes mellitus, ${ }^{19}$ and primary biliary cirrhosis. ${ }^{20}$ Myocyte expression of HLA-DR was therefore compared in biopsy specimens from polymyositis and those from other muscle disorders, which also had a prominent inflammatory cell infiltrate. Concurrently, cellular infiltrates were characterised using monoclonal antibodies to mononuclear cells.

\section{Material and methods}

A series of muscle biopsy specimens from 15 cases of clinical polymyositis were available for study; all had typical diagnostic histological feature ${ }^{21}$ including an inflammatory infiltrate. For comparision, we selected a group of specimens which were not of primary inflammatory muscle disease, but which also had a high mononuclear infiltrate. In this group were six cases of muscular dystrophy (two Duchenne, four facio-scapulo-humeral) and one of acute denervation 
(motor neurone disease). Twelve entirely normal biopsy specimens were also included in the study.

All specimens were obtained by needle biopsy from the quadriceps muscle-vastus lateralis. Shortly after biopsy tissue samples were snap frozen in isopentane in liquid nitrogen. Frozen cryostat sections $8 \mu \mathrm{m}$ thick were stored at $-25^{\circ} \mathrm{C}$ for both conventional histological and histochemical studies as well as for immunohistochemical analysis.

\section{IMMUNOHISTOCHEMISTRY}

To investigate myocyte expression of HLA-DR and to characterise the inflammatory infiltrate, serial unfixed frozen sections were stained by a three stage alkaline phosphatase-antialkaline phosphatase (APAAP) technique using the following commercially available monoclonal antibodies as primary antisera:

Dako HLA DR (M704:Dako) This reacts with the $\beta$ chain of products coded for by the gene loci DP, DQ, and $\mathrm{DR},{ }^{22}$ and was diluted 1 in 20 in Tris buffered saline (TBS).

$M T 1$ (Eurodiagnostics) This identifies all $\mathrm{T}$ lymphocytes and macrophages ${ }^{2324}$ and was diluted 1 in 10 in TBS.

MBI (Eurodiagnostics) This identifies all B lymphocytes and a proportion of $\mathrm{T}$ lymphocytes ${ }^{2324}$ and was diluted 1 in 20 in TBS.

Briefly, the APAAP technique was performed as follows. Sections were preincubated with normal rabbit antiserum ( 1 in 5 in TBS;Dako) to reduce nonspecific background reactivity, then allowed to react overnight with each of the three primary antisera at $4^{\circ} \mathrm{C}$. The secondary antiserum (rabbit antimouse, 1 in 50 in TBS;Dako) was then added, followed by the APAAP complex ( 1 in 100 in TBS;Dako). A red reaction product was generated by the developer consisting of fast TR red with naphthol ASB1 phosphate in veronal acetate, levamisole being added to block endogenous phosphatase activity. Controls had primary antibody omitted.

\section{MUSCLE EXPRESSION OF HLA-DR}

Muscle fibres were only considered positive for HLADR when circumferential sarcolemmal staining was present. The presence or absence of muscle cytoplasmic staining was also noted. Sarcolemmal reaction intensity was compared with that of stromal mononuclear cells and vascular endothelium, both of which are normally known to express HLA-DR, ${ }^{17}$ thereby acting as positive internal controls. Intensity of reaction was graded from $1+$ to $3+$ corresponding to weak, moderate, and strong staining.

\section{INFLAMMATORY CELLS}

With the antibodies MB1 and MT1 the morphological cell types identified, together with their distribution within the specimens, were defined. The approximate proportion of the total mononuclear infiltrate reacting with each antibody was also determined. Sections stained with all three antibodies were used to quantify subjectively the magnitude of the inflammatory infiltrate from $1+$ to $3+$ (sparse, moderate, and heavy).

\section{Results}

MUSCLE EXPRESSION OF HLA-DR

Muscle fibres within all 12 normal muscle biopsy specimens were negative for HLA-DR. By contrast, groups of muscle fibres in all 15 cases of polymyositis expressed this antigen (fig 1). Circumferential sarcolemmal staining was moderate or strong in all cases, and diffuse weaker cytoplasmic reactivity was seen in all but one case (table). Fibres exhibiting cytoplasmic staining also had positive sarcolemmal staining but the reverse was not true. Small fibres in polymyositis tended to exhibit stronger sarcolemmal and cytoplasmic staining, these generally being situated in close proximity to the mononuclear infiltrate, often in a

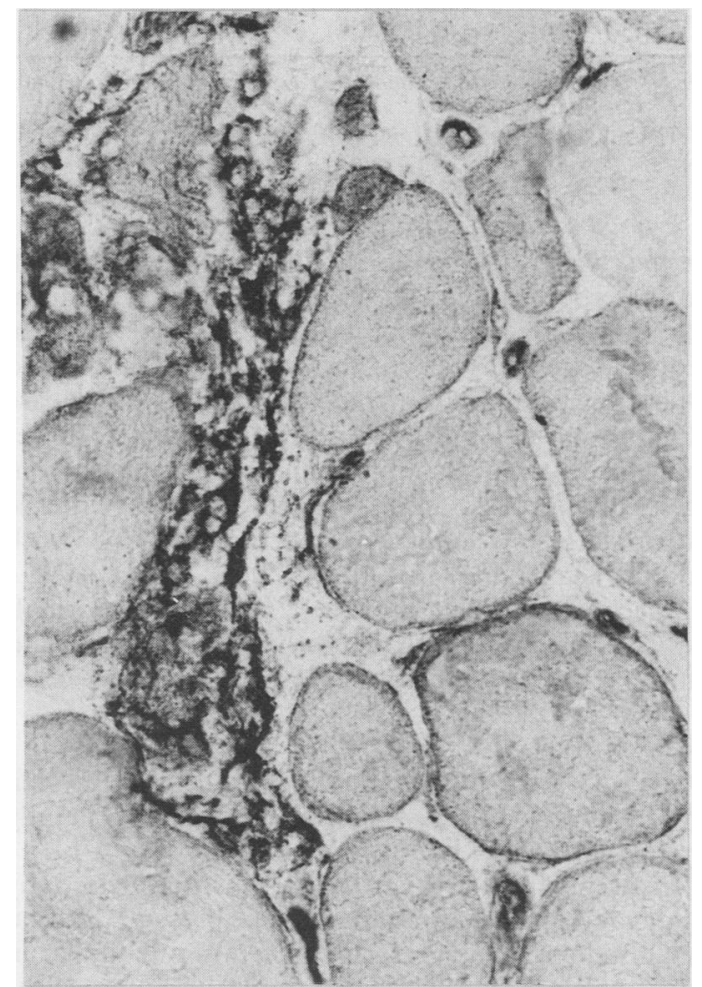

Fig 1 Polymyositis. Myocyte expression of HLA-DR is seen, with both sarcolemmal and cytoplasmic staining present. Large aggregate of mononuclear cells is strongly positive. ( $A P A A P$.) 
Table Intensity of mononuclear inflammatory infiltrate and muscle expression of $H L A-D R$ in diseased muscle

\begin{tabular}{|c|c|c|c|c|}
\hline \multirow{2}{*}{$\begin{array}{l}\text { Case } \\
\text { No }\end{array}$} & \multirow[b]{2}{*}{ Diagnosis } & \multirow{2}{*}{$\begin{array}{l}\text { Mono- } \\
\text { nuclear } \\
\text { infiltrate }\end{array}$} & \multicolumn{2}{|c|}{$\begin{array}{l}\text { Muscle expression } \\
\text { of } H L A-D R\end{array}$} \\
\hline & & & Sarcolemmal & Cytoplasmic \\
\hline \multirow{16}{*}{$\begin{array}{r}1 \\
2 \\
3 \\
4 \\
5 \\
6 \\
6 \\
7 \\
8 \\
9 \\
10 \\
11 \\
12 \\
13 \\
14 \\
15 \\
16\end{array}$} & Polymyositis & $2+13+$ & $3+$ & Positive \\
\hline & 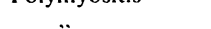 & & $3+$ & Positive \\
\hline &.. & $1+/ 2+$ & $3+$ & Positive \\
\hline & .. & $1+12+$ & $2+$ & Negative \\
\hline &.. & $1+12+$ & $2+$ & Positive \\
\hline & ". & $1+/ 2+$ & $2+$ & Positive \\
\hline & ." & $1+/ 2+$ & $2+$ & Positive \\
\hline & $"$ & $2+13+$ & $3+$ & Positive \\
\hline & $"$ & $3+$ & $3+$ & Positive \\
\hline & " & $2+$ & $3+$ & Positive \\
\hline & ". & $2+$ & $2+13+$ & Positive \\
\hline & . & & $3+$ & Positive \\
\hline & ". & $1+12+$ & $2+$ & Positive \\
\hline & ," & $1+12+$ & $2+$ & Positive \\
\hline & & $2+$ & $2+$ & Positive \\
\hline & Duchenne & & & \\
\hline \multirow{2}{*}{$\begin{array}{l}17 \\
18\end{array}$} & dystrophy & $\begin{array}{l}1+12+ \\
2+\end{array}$ & $\begin{array}{l}\text { Negative } \\
\text { Negative }\end{array}$ & $\begin{array}{l}\text { Negative } \\
\text { Negative }\end{array}$ \\
\hline & Facio-scapulo- & & & \\
\hline \multirow{4}{*}{$\begin{array}{l}19 \\
20 \\
21 \\
22\end{array}$} & humeral dystrophy & $2+/ 3+$ & Negative & Negative \\
\hline & $"$ & $\begin{array}{l}2+ \\
3+\end{array}$ & $\begin{array}{l}\text { Negative } \\
\text { Negative }\end{array}$ & $\begin{array}{l}\text { Negative } \\
\text { Negative }\end{array}$ \\
\hline & $"$ & $3+$ & Negative & Negative \\
\hline & $\begin{array}{l}\text { Motor neurone } \\
\text { disease }\end{array}$ & $1+12+$ & Negative & Negative \\
\hline
\end{tabular}

Quantitation of mononuclear infiltrate $1+=$ sparse, $2+=$ moderate, $3+=$ heavy.

Quantitation of sarcolemmal staining $1+=$ weak, $2+=$ moderate, $3+=$ strong.

perifascicular distribution. Other muscle cells with normal appearances and situated some distance from the main inflammatory infiltrates were also positive. In biopsy specimens from the six dystrophies (two Duchenne, four facio-scapulo-humeral) and one case of motor neurone disease no positive muscle fibres were present (fig 2), despite biopsy specimens from these cases having been selected as having intense inflammatory infiltrates comparable with polymyositis (table).

Specimens from all 34 cases ( 22 diseased, 12 normal) exhibited strong vascular endothelial reactivity as did most of the stromal mononuclear inflammatory cells.

\section{INFLAMMATORY CELLS}

Only very occasional mononuclear cells were seen within normal biopsy specimens, being generally positive with MT1 but not with MB1.

In all cases of polymyositis and muscular dystrophy aggregates of mononuclear cells were present; the total magnitude of inflammatory infiltration was similar in both groups of disorders (table). Mononuclear aggregates were randomly distributed throughout the muscle fascicles in dystrophies but predominated in the perifascicular areas in polymyositis. These aggregates tended to concentrate in areas where small, round muscle fibres were found in both groups of disorders.

In all specimens from diseased muscle the antibody MT1 positively identified most of the total cellular infiltrate by surface staining. Cells that were morphologically small lymphocytes and other, larger cells with the appearances of macrophages were stained with this antibody. This contrasted with $\mathrm{MB} 1$ positive cells, which morphologically were all lymphocytes and were found in only small numbers in all abnormal specimens. Surface staining of lymphocytes was also seen. Virtually all of the infiltrating mononuclear cells, both of lymphoid (including small) and macrophage (including large) type, expressed HLA-DR.

Myocyte expression of HLA-DR generally paralleled the magnitude of the total inflammatory infiltrate in polymyositis: cases in which the infiltrate was moderate or heavy usually exhibited strong sarcolemmal positivity (table).

\section{Discussion}

In all cases of polymyositis, skeletal muscle expression

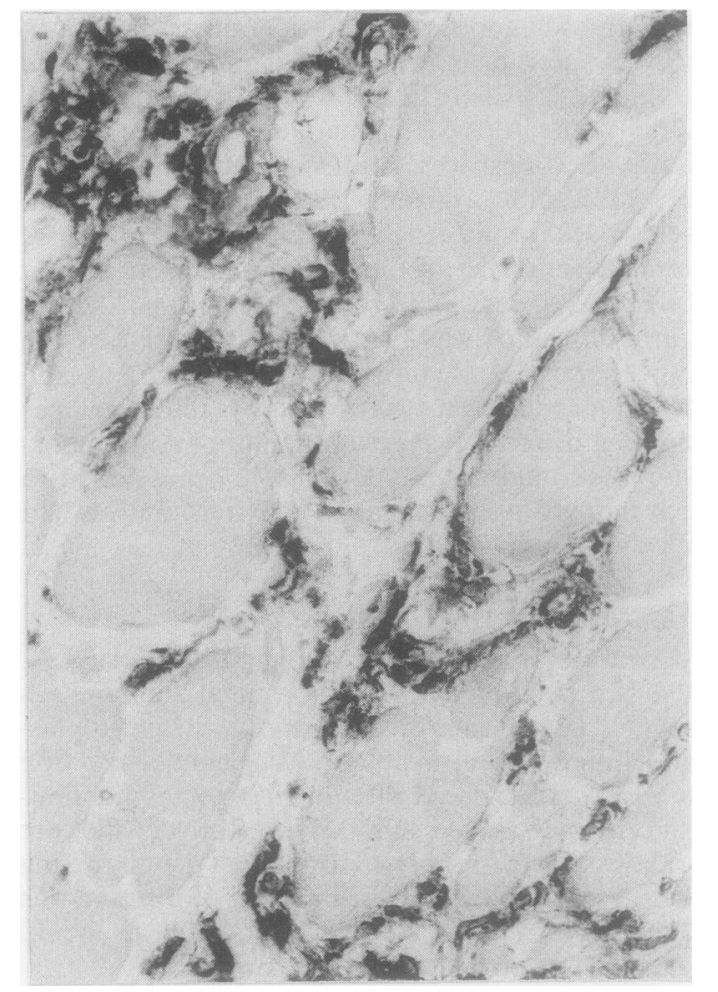

Fig 2 Facio-scapulo-humeral dystrophy. Aggregates of infiltrating mononuclear cells are positive as is vascular endothelium, but myocytes are negative for $H L A-D R$. ( $A P A A P$.) 
of class II histocompatibility antigens (HLA-DR) occurred as shown using a three stage APAAP technique with a monoclonal antibody to $\beta$ chains of this glycoprotein. Expression can therefore be considered to be aberrant; normal skeletal muscle does not express this antigen, and this was confirmed in this study and has been previously described by others. ${ }^{517}$

To our knowledge, this is the first time that clearly defined muscle expression of HLA-DR has been described in any muscle disorder, although two immunohistochemical studies ${ }^{56}$ have described ill defined, hazy deposits of this antigen around and within damaged muscle fibres, but in only a small proportion of cases of polymyositis. Possible reasons for the failure to demonstrate HLA-DR expression on muscle fibres in all cases of polymyositis in these studies could be that a different monoclonal antibody was used (DA2) and that the less sensitive techniques of indirect immunofluorescence ${ }^{5}$ and indirect immunoperoxidase $^{6}$ were used. Other studies have used antibodies to class II histocompatibility antigens to characterise the inflammatory infiltrate in polymyositis and dystrophies, but no mention of muscle reactivity was stated. ${ }^{825}$

Muscle expression of HLA-DR seems to be specific for the group of primary inflammatory myopathies collectively termed polymyositis. None of the cases of muscular dystrophy or the single case of acute denervation exhibited this feature. In these latter disorders the inflammatory infiltrate was considered to be a secondary response to muscle fibre degeneration or death, in contrast to the situation in polymyositis in which cell mediated immune damage to skeletal muscle was most likely a primary pathogenetic mechanism. ${ }^{121011}$ Our finding of HLA-DR expression on muscle fibres only in polymyositis is supportive evidence for the possible key part played by aberrant expression of this important glycoprotein in the aetiology and pathogenesis of this disorder. Similar findings have been described in other autoimmune type diseases-for example, of the pancreas, ${ }^{19}$ thyroid,$^{18}$ and bile ducts. ${ }^{20}$ In the pathogenesis of these disorders aberrant HLA-DR expression probably leads to activation of T4 (helper) lymphocytes, ${ }^{14}$ thereby triggering cell mediated immune damage.

In other organs and tissues, however, expression of class II antigen by the parenchymal cells occurs during inflammation as a non-specific response to the presence of an inflammatory infiltrate, irrespective of the precise aetiology of the inflammation. This has been described in pulmonary alveolar epithelium, ${ }^{26}$ duodenal mucosa, ${ }^{27}$ and in the colon, ${ }^{28}$ as well as in a range of other tissues. It is most likely that induction of HLA-DR in these situations occurs in response to the presence of the lymphokine $\gamma$-interferon, although other soluble mediators may be important. ${ }^{29}$ Non- specific induction of HLA-DR expression, however, is not apparent in skeletal muscle. No expression was found in biopsy specimens from muscular dystrophy or in the solitary case of motor neurone disease, despite the intensity of the inflammatory infiltrate present in the cases selected (table).

Our findings concerning the characterisation of the inflammatory infiltrate agree with those of previous studies. ${ }^{69830}$ In both polymyositis and dystrophies with an inflammatory component $T$ lymphocytes and macrophages are the predominant cell types, with only small numbers of B lymphocytes being found. The distribution of the inflammatory cells in each biopsy was also characteristic for the disorders studied.

HLA class I (HLA-A,B,C) antigen expression by skeletal muscle differs from that described here for HLA-DR. Although normal muscle is also negative, ${ }^{31}$ increased muscle fibre expression of HLA-A,B,C is found in a variety of disorders including polymyositis and muscular dystrophies. ${ }^{631}$ Its presence on muscle fibres is therefore not specific for any particular group of muscle disorders.

The specificity of HLA-DR expression by skeletal muscle in polymyositis may prove of value in histopathological diagnosis. Many disorders, including dystrophies (especially facio-scapulo-humeral dystrophy), ${ }^{21}{ }^{31}$ often have a pronounced inflammatory component. Although clinical and histological features are used to differentiate these conditions in most instances, muscle expression of HLA-DR may be a useful adjunct in especially problematic cases.

We thank the staff of the Special Histology and Histochemistry laboratories, Leicester Royal Infirmary for technical assistance and Mrs L Bailey for typing the manuscript.

\section{References}

1 Behan WMH, Behan PO. Immunological features of polymyositis/dermatomyositis. Springer Semin Immunopathol 1985;67:267-93.

2 Whitaker JN. Inflammatory myopathy: a review of etiologic and pathogenetic factors. Muscle Nerve 1982;5:573-92.

3 Oxenhandler R, Adelstein EH, Hart MN. Immunopathology of skeletal muscle: the value of direct immunofluorescence in the diagnosis of connective tissue disease. Hum Pathol 1977;8: 321-8.

4 Heffner RR. Barron SA, Jenis EH, Valeski JE. Skeletal muscle in polymyositis. Immunohistochemical study. Arch Pathol Lab Med 1979;103:310-13.

5 Rowe DJ, Isenberg DA, McDougall J, Beverley PCL. Characterisation of polymyositis infiltrates using monoclonal antibodies to human leucocyte antigens. Clin Exp Immunol 1981;45:290-8.

6 Rowe D, Isenberg DA, Beverley PCL. Monoclonal antibodies to human leucocyte antigens in polymyositis and muscular dystrophy. Clin Exp Immunol 1983;54:327-36.

7 Arahata K, Engel AG. Mononuclear antibody analysis of mononuclear cells in myopathies. I: Quantitation of subsets according to diagnosis and sites of accumulation and demonstration and 
counts of muscle fibres invaded by $\mathrm{T}$ cells. Ann Neurol 1984;16:193-208.

8 Giorno R, Barden MT, Kohler P, Ringel SP. Immunohistochemical characterisation of the mononuclear cells infiltrating muscle of patients with inflammatory and non-inflammatory myopathies. Clin Immunol Immunopathol 1984;30:405-12.

9 Lemoine NR, Ryan JF, Cox EL, Mayston V, Revell PA, Swash M. Immunohistochemical analysis of mononuclear cell subsets in inflammatory and non-inflammatory myopathies. J Clin Pathol 1986;39:271-44.

10 Currie S, Saunders M, Knowles M, Brown A. Immunological aspects of polymyositis. The in vitro activity of lymphocytes on incubation with muscle antigen and with muscle cultures. $Q J$ Med 1971;40:63-84.

11 Dawkins RL, Mastaglia FL. Cell-mediated cytotoxicity to muscle in polymyositis. Effect of immunosuppression. $N$ Engl J Med 1973;288:434-8.

12 Thorsby E. Structure and function of HLA molecules. Transplant Proc 1987;19:29-35.

13 Dasgupta JD, Cemach K, Dubey DP, Yumis EJ, Amos DB. The role of class I histocompatibility in the regulation of T-cell activation. Proc Natl Acad Sci USA 1987;84:1094-8.

14 Benacerraf B. Significance and biological function of class II MHC molecules. Am J Pathol 1985;120:334-43.

15 Daar AS, Fuggle SV, Fabre JW, Tuig A, Morris PJ. The detailed distribution of HLA-A,B,C antigens in normal human organs. Transplantation 1984;38:287-92.

16 Unanue ER, Allen PM. Comment on the findings of Ia expression in non-lymphoid cells. Lab Invest 1986;55:123-5.

17 Daar AS, Fuggle SV, Fabre JW, Tuig A, Morris PJ. The detailed distribution of MHC class II antigens in normal human organs. -Transplantation 1984;38:293-8.

18 Foulis AK. Class II major histocompatibility complex and organ specific autoimmunity in man. J Pathol 1986;150:5-11.

19 Foulis AK. The pathogenesis of beta cell destruction in type I (insulin-dependent) diabetes mellitus. $J$ Pathol 1987;152: 141-8.

20 Ballardini G, Bianchi FB, Doniach D, et al. Aberrant expression of HLA-DR antigens on bile duct epithelium in primary biliary cirrhosis: relevance to pathogenesis. Lancet 1984;ii:1009-13.

21 Dobowitz V. Muscle biopsy. A practical approach. 2nd edition. London: Baillière Tindall, 1985.
22 Collings LA, Poulter LW. Janossy G. The demonstration of cell surface antigens on T cells, B cells and accessory cells in paraffinembedded human tissues. $J$ Immunol Methods 1984;75:227-39.

23 West KP, Warford A, Allen M. Campbell AC. Lauder I. The demonstration of B-cell, T-cell and myeloid antigens in paraffin sections. J Pathol 1986;150:89-101.

24 Poppema S, Hollema H, Visser L, Vos H. Monoclonal antibodies (MT1 MT2, MB1, MB2, MB3) reactive with leucocyte subsets in paraffin-embedded tissue sections. Am J Pathol 1987: 127:418-29.

25 Engel AG, Arahata I. Mononuclear cells in myopathies: quantitation of functionally distinct subsets, recognition of antigen-specific cell-mediated cytotoxicity in some diseases, and implications for the pathogenesis of the different inflammatory myopathies. Hum Pathol 1986;17:704-21.

26 Kallenberg CGM, Schilizzi BM, Beaumont F, Leij L, Poppema S, The TH. Expression of class II major histocompatibility complex antigens on alveolar epithelium in interstitial lung disease: relevance to pathogenesis of idiopathic pulmonary fibrosis. J Clin Pathol 1987:40:725-33.

27 Barbatis C, Crouch S. Immunohistochemical study of HLA-DR antigens and lymphocytes in inflammatory duodenal diseases. J Pathol 1987; 152:227A-8A.

28 McDonald GB. Jewell DP. Class II antigen (HLA-DR) expression by intestinal epithelial cells in inflammatory disease of colon. J Clin Pathol 1987;40:312-7.

29 Halloran PF, Wadgymar A, Autenried P. The regulation of expression of major histocompatibility complex products. Transplantation 1986;41:413-20.

30 Munsat TL, Piper D, Cancilla P, Mednick J. Inflammatory myopathy with facioscapulohumeral distribution. Neurolog. 1972:22:335-47.

31 Appleyard ST, Dubowitz V, Dunn MJ, Rose M. Increased expression of HLA-ABC class I antigens by muscle fibres in Duchenne muscular dystrophy, inflammatory myopathy, and other neuromuscular disorders. Lancet 1985;i:361-3

Requests for reprints to: $\operatorname{Dr}$ A Fletcher, Consultant Histopathologist, Department of Histopathology, Leicester Royal Infirmary, Leicester LE1 5WW, England. 